\title{
Silicon Photodiodes for Low Penetration Depth Beams such as DUV/VUV/EUV Light and Low-Energy Electrons
}

\author{
Lis K. Nanver \\ Delft Institute of Microsystems and Nanoelectronics (DIMES) \\ Delft University of Technology \\ The Netherlands
}

\section{Introduction}

When the attenuation lengths of beams in silicon are well below a micron, a high responsivity of silicon photodiodes can only be reached if the photo-sensitive region for detection is close to the surface. The direct way to achieve this is to create ultrashallow, damage-free junctions. This has in fact been one of the challenges that the silicon-basedtechnology CMOS has been struggling with for the last two decades: such junction depths are specified in the International Technology Roadmap for Semiconductors (ITRS) in order to continue the aggressive downscaling of MOS devices as dictated by Moore's law (ITRS 2009). However, although technologies have been developed for junctions as shallow as $200 \mathrm{~nm}$ and below, the resulting diodes are mainly far from being damage-free (Borland et al., 2010). Schottky-type junctions represent the limit in shallowness, but are mainly unattractive due to a high reverse leakage current, surface recombination, reflection and absorption in the front metal, and low surface electric field. Therefore, silicon photodiode research has directed efforts towards increasing the sensitivity near the silicon surface by creating damage-free doped regions with an electric field, also outside the depletion region, that transports the generated carriers to the terminals. An alternative method has also been demonstrated where a $\mathrm{Si}-\mathrm{SiO}_{2}$ interface is used to create an inversion layer with a conductive channel at the interface for transporting the generated carriers. Photodiodes that have found application for the detection of low-penetration beams have been produced by such methods, but they have issues such as poor process control, low yield, and poor radiation hardness (Funsten et al., 2004; Silver et al., 2006; Solt et al., 1996; Tindall et al., 2008).

This chapter reviews a boron-layer silicon photodiode technology that can be used to create an extremely shallow $\mathrm{p}^{+} \mathrm{n}$ junction, and therefore no "tricks" are needed to place the photosensitive surface within nanometers of the Si surface. An amorphous boron (a-B) layer, which can be down to about $1 \mathrm{~nm}$ thick, is formed on the surface of the silicon by chemical vapor deposition (CVD) of pure boron. From this layer an extremely shallow doping of the Si surface is effectuated, forming a $\mathrm{p}^{+} \mathrm{n}$ junction that can be readily made in the $\sim 1-10 \mathrm{~nm}$ junction-depth range. This is achieved by applying low processing temperatures from 500 to $700{ }^{\circ} \mathrm{C}$. The properties of the a-B layer, both chemically and electrically, are responsible 
for achieving exceptional photodiode performance that surpasses that of other existing technologies on points such as internal/external quantum efficiency, dark current, uniformity and degradation of responsivity. At the same time the B-layer process is fully compatible with Si front-end technology, and these photodiodes readily lend themselves to detector integration schemes that allow low parasitic resistance and capacitance as well as on-chip integration with other electronic elements.

These properties have lead to a fast qualification for production of several types of B-layer photodiode detectors for industrial applications. Three examples of such applications are described in Section 4:

- $\quad$ vacuum ultraviolet (VUV) detectors (Shi et al., 2010) for which the attenuation length of the light in $\mathrm{Si}$ is as low as $5 \mathrm{~nm}$. This includes the deep ultraviolet (DUV) wavelength of $193 \mathrm{~nm}$ used in advanced lithography systems (Sarubbi et al., 2008a);

- extreme ultraviolet (EUV) detectors (Sarubbi et al., 2008b) for detecting light at a wavelength of $13.5 \mathrm{~nm}$. This is essentially soft X-rays that have an attenuation length of $700 \mathrm{~nm}$ in Si. This wavelength has been chosen for use in future advanced lithography tools;

- low-energy electrons that for energies around $500 \mathrm{eV}$ have ranges in Si below $\sim 10 \mathrm{~nm}$ (Šakić et al., 2010b). Particularly the application in Scanning Electron Microscopes (SEMs) is explored here.

\section{Nanometer-deep junction formation from $\alpha$-boron layers}

The deposition of $\mathrm{a}-\mathrm{B}$ layers is performed in a commercially available epitaxial CVD reactor using diborane $\left(\mathrm{B}_{2} \mathrm{H}_{6}\right)$ and hydrogen $\left(\mathrm{H}_{2}\right)$ as the gas source and carrier gas, respectively. The details of this process, that can be performed either at atmospheric or reduced pressures are given in (Sarubbi et al., 2010a) for deposition temperatures ranging from 500 to $700{ }^{\circ} \mathrm{C}$ and various doping gas conditions. The formation of the boron layer is slower the lower the temperature and the diborane partial pressure, but at high gas-flow rates, which provide good conditions for segregation of boron atoms on the Si surface, it is essentially controlled by the exposure time. An example is shown in Fig. 1 for constant temperature, pressure and $\mathrm{B}_{2} \mathrm{H}_{6}$ flow-rate, where the deposition rate is constant for depositions longer than $\sim 1 \mathrm{~min}$.

An example of a B-layer formed after 10 min $\mathrm{B}_{2} \mathrm{H}_{6}$ exposure at atmospheric pressure for a temperature of $700{ }^{\circ} \mathrm{C}$ is seen in the high-resolution transmission electron microscopy (HRTEM) image of Fig. 2, where the segregation of B atoms in an amorphous layer and the reaction with silicon atoms to form a boron-silicide phase at the interface can be discerned. The a-B layer is a conductive semi-metal found to have a high resistivity of $\sim 10^{4} \Omega \mathrm{cm}$.

To maintain an ultrashallow junction depth that is only determined by thermal diffusion of the boron into the $\mathrm{Si}$ at the given processing temperature, it is important that the doping process is free of defects that can cause boron-enhanced or transient-enhanced diffusion (TED) effects. This was evaluated by examining the out-diffusion of epitaxially grown Bdoped Si markers after long B-depositions at $700{ }^{\circ} \mathrm{C}$ (Sarubbi et al., 2010b). Layers containing more than $10^{17} \mathrm{~cm}^{-2}$ boron atoms were deposited, giving about $1 \mathrm{~nm}$ of boron silicidation at the interface, but the results gave no indication of TED effects. This result substantiates the conclusion, also drawn from the excellent properties found for B-layer photodiodes, that an effectively damage-free junction is formed.

The c-Si surface is doped up to the solid solubility solely by thermal diffusion. For $500{ }^{\circ} \mathrm{C}$ depositions this gives junction depths of $\sim 1 \mathrm{~nm}$, and at $700{ }^{\circ} \mathrm{C}$ junctions of less than $10 \mathrm{~nm}$ 


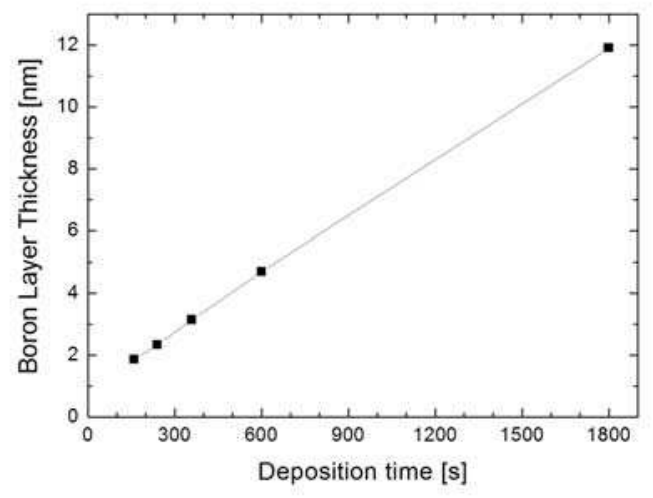

Fig. 1. Thickness of boron layers measured by ellipsometry as a function of time for depositions at a pressure of 760 Torr, a temperature of $700{ }^{\circ} \mathrm{C}$, and a diborane flow-rate of 490 sccm (Šakić et al., 2010a).

a)

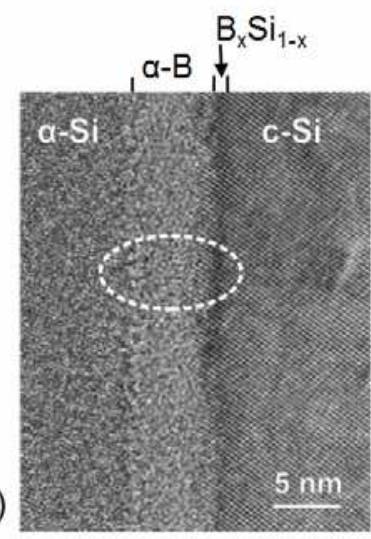

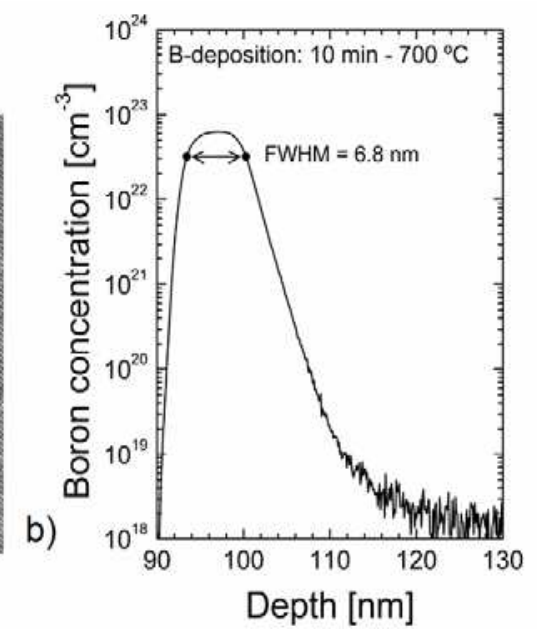

Fig. 2. (a) High-resolution TEM image and (b) SIMS profile $\left(\mathrm{O}_{2}{ }^{+}\right.$primary ion beam at $\left.1 \mathrm{keV}\right)$ of an as-deposited B-layer formed on a (100) Si surface at $700{ }^{\circ} \mathrm{C}$ after $10 \mathrm{~min} \mathrm{~B}_{2} \mathrm{H}_{6}$ exposure (Sarubbi et al., 2010b).

deep are readily formed. In the latter case the doping will be as high as $\sim 2 \times 10^{19} \mathrm{~cm}^{-3}$ (Vick \& White, 1969). For further doping by post-deposition thermal drive-in of the boron, the formation of the a-B layer has two distinct advantages: it acts as an abundant source of dopants and also prevents boron desorption from the Si surface. This is in contrast to the results of other works that also aimed to use depositions from diborane and subsequent thermal annealing to obtain higher dopant activation and deeper junction depths (Inada et al., 1991), (Kim et al., 2000). The difference lies in the fact that in these cases the diborane exposure conditions were designed to avoid or minimize the formation of a distinct layer of boron. To avoid B-desorption during drive-in, an oxide capping layer was proposed, but still the available $\mathrm{B}$ will be limited under the given deposition conditions. 
To create a $\mathrm{p}^{+} \mathrm{n}$ diode the B-deposition can be performed with high selectivity in a silicon dioxide window on an n-type c-Si surface. This requires that the Si surface is native-oxide free, which can be achieved by HF dip-etching, possibly followed by hydrogen pre-baking such as those seen in Fig. 3. Nevertheless, the a-B layer is continuous and uniform across the $\mathrm{Si}$, and the deposited thickness is independent of the window size. This isotropic boron coverage, selectively on all exposed Si surfaces, considerably enhances the integration potentials of this process among other things for fabricating high-quality diodes.
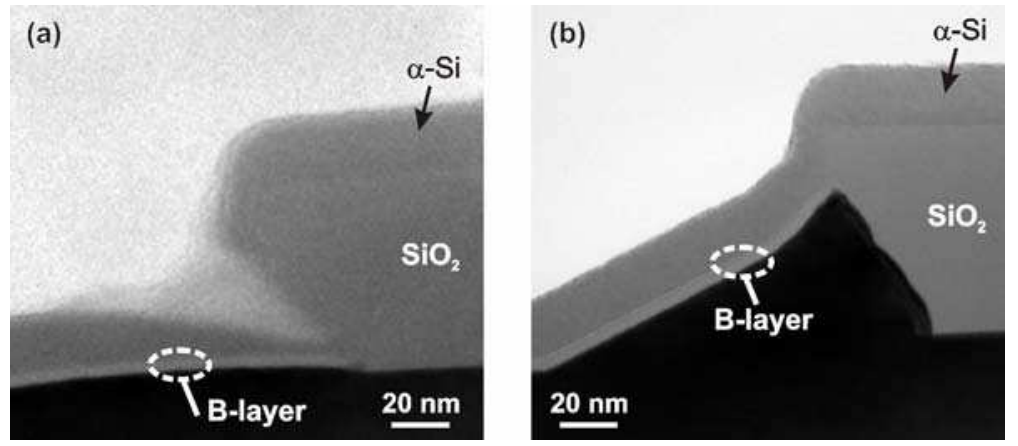

Fig. 3. TEM images of contact windows treated with a $2.5 \mathrm{~min}$ B-deposition at $700{ }^{\circ} \mathrm{C}$. The $\mathrm{SiO}_{2}$ etch geometry has been induced by a low-pressure in-situ thermal cleaning at $900^{\circ} \mathrm{C}$ before diborane exposure (Sarubbi et al., 2010b).

\section{Electrical characteristics of nanometer-deep junctions}

Nanometer deep p-n junctions such as the B-layer junctions may exhibit electrical currentvoltage characteristics that deviate considerably from those of conventional deep junctions. For the first, the metal acts as a sink for minority carrier injection that hence increases as the junction becomes more and more shallow. Thus the dark current is increased. Moreover, the doping of the junction can become so low that it is completely depleted. This leads to punchthrough phenomena that also will increase the current through the diode, and again also increase the dark current, often by decades.

\subsection{Theoretical considerations}

Consider the case of an n-Si substrate that is exposed to a process for $\mathrm{p}$-doping the surface and that this, upon metallization, may result in anything between a deep metal/p-Si/n-Si (m-p-n) junction and a metal/n-Si (m-n) Schottky diode where effectively no doping is realized. The electron and hole currents in the different situations that can occur in the transition from a deep to an ultrashallow through to a Schottky junction are illustrated by the device simulations shown in Fig. 4. For a detailed analysis of these I-V characteristics, including an analytical model that unifies the standard Schottky and p-n diode formulations, the reader is referred to (Popadić et al., 2009). Three main types of diode behavior can be identified:

(a) an m-n Schottky diode: the diode current is dominated by the injection of the majority carrier (electrons) from the semiconductor into the metal. At the same time, a very small current of holes is injected from the metal into the semiconductor. 
(b) an m-p-n diode fully-depleted by a high Schottky barrier height (SBH): an ultrashallow heavily-doped p-type region is created at the surface of the n-type substrate, and the contact to this region is a Schottky contact. Under reverse and small forward bias, the p-region is fully depleted by the metal-semiconductor depletion region and the diode shows the electrical characteristics of an n-Schottky. The current is dominated by electron injection into the metal, but the effective SBH is so high that the total current is much lower than the pure Schottky case and also the hole-current is much higher. At a high enough forward-bias voltage, the p-region can become non-depleted, effectively reducing the electron current to the point where the device behaves as an m-p-n junction diode with the hole-current level approaching that of the electron current. It should be noted that the transition from Schottky-like to pn-junction-like behavior can of course also occur in the reverse voltage region depending on the doping levels.

(c) a non-depleted m-p-n diode: the diode current is dominated by the injection of holes from the $\mathrm{p}^{+}$region into the $\mathrm{n}$-substrate and the hole-current is much higher than in cases (a) and (b). For shallow junctions the metal forms a sink for the minority carrier electron injection, and this will give an increase of the otherwise very low electron-current for junction depths below $\sim 20 \mathrm{~nm}$. In the example treated in Fig. 4c the electron current becomes about as high as the hole current for a junction depth $d=10 \mathrm{~nm}$. As the junction depth goes to $d=0$, the electron current will increase to levels far above the hole current to finally reach Schottky current levels as high as that seen in Fig. 4a.

\subsection{Electrical properties of $\alpha$-B layer diodes}

The different diode I-V characteristics described in the previous section have all been observed in the case of B-layer diodes. An example is given in Fig. 5 where the results are displayed for different B-layer deposition times and temperature followed by metal contacting with Al. Even a very short $1 \mathrm{~s}$ deposition lowers the current level decades below the pure Al Schottky level, and already for a couple-of-minutes-long deposition the saturation current approaches a value that is typical for conventional deep junctions. If the boron semi-metal layer was functioning as a sink for the electron injection (Sarubbi et al., 2010b, 2010c), this would not be expected for these junction depths of well below $10 \mathrm{~nm}$. In fact, it has been established experimentally that the $a-B$ layer attenuates rather than sinks the electron injection, which also is evidence that it is not pure metallic in this form. This attenuation effect has the attractive consequence that these extremely shallow junctions can be produced with much lower dark currents than would otherwise be possible.

A drawback of the non-metallic nature of the a-B layer is the fact that it has a high resistivity of $\sim 10^{4} \Omega \mathrm{cm}$. This results in a high series resistance to the contact metal even for $\mathrm{nm}$ thin layers, which is clearly seen in Fig. 5 as the large attenuation of the I-V curves at high forward biasing for the longer deposition times. A suitable compromise between series resistance and saturation current level is often found for deposition times of about $1 \mathrm{~min}$ where the a-B layer thickness is below the tunneling thickness of $\sim 3 \mathrm{~nm}$.

\section{Integration of B-layer photodiodes in detectors}

The B-layer diode technology is fully compatible with silicon front-end processing, a fact that has been of crucial importance for the realization of the three detector types developed for industrial applications and discussed in the following. Not only have special detector 


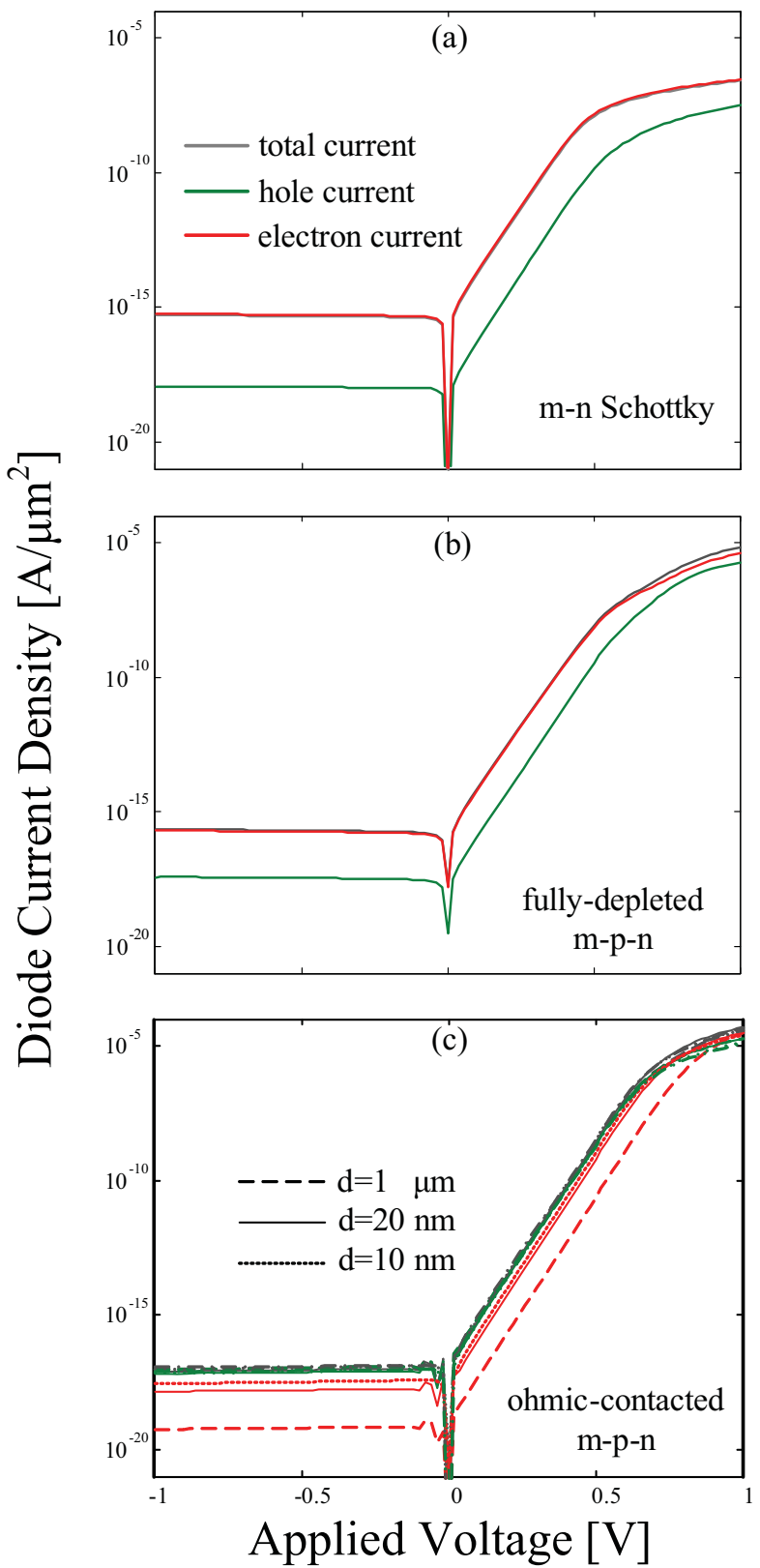

Fig. 4. Simulated output characteristics of (a) an m-n Schottky diode with $\mathrm{SBH}=0.85 \mathrm{~V}$, (b) a fully-depleted m-p-n diode with $\mathrm{SBH}=0.75 \mathrm{~V}$ and junction depth $\mathrm{d}=20 \mathrm{~nm}$, and (c) ohmiccontacted m-p-n diodes, both with $\mathrm{N}_{\mathrm{A}}=1 \times 10^{20} \mathrm{~cm}^{-3}$. The substrate doping is in all cases $\mathrm{N}_{\mathrm{D}}=1 \times 10^{15} \mathrm{~cm}^{-3}$. 


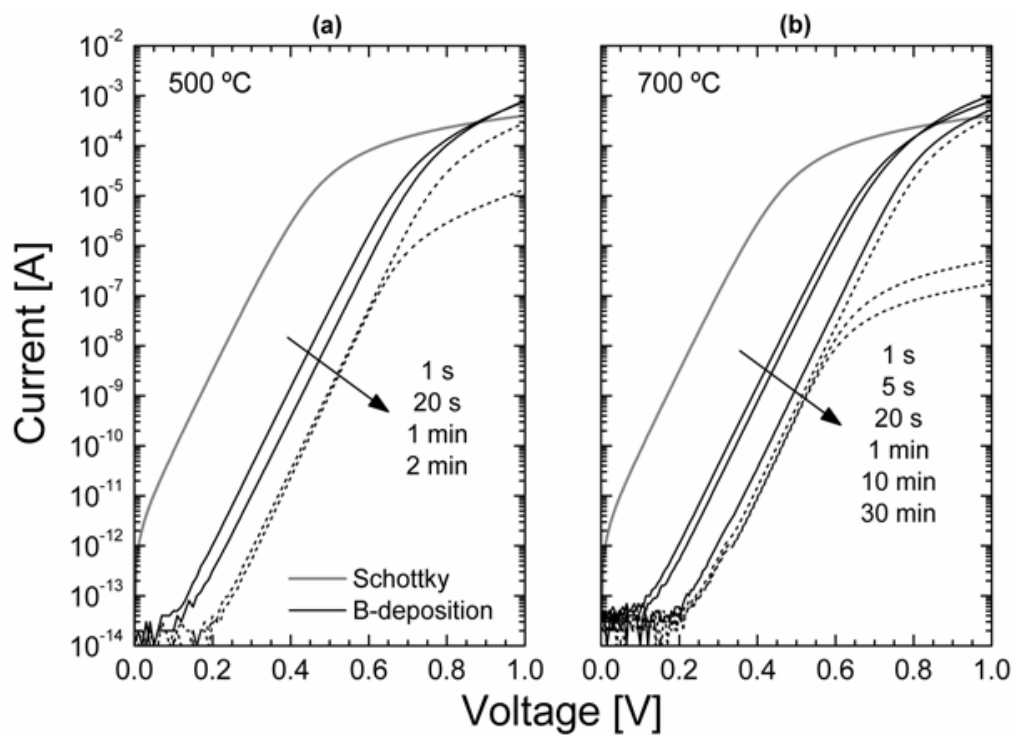

Fig. 5. Diode I-V characteristics for various B-layer deposition times at either (a) $500{ }^{\circ} \mathrm{C}$ or (b) $700{ }^{\circ} \mathrm{C}$. The anode area is $2 \times 1 \mu^{2}$. For comparison, the I-V curve of a Schottky diode is also included (Sarubbi et al., 2010a).

geometries been realized, but the photodiodes were also integrated with other on-chip active and passive components. For example, bipolar transistors were integrated in EUV detectors as on-chip temperature sensors. The doping regions of such extra devices can often be processed entirely before the anode B-layer deposition since it can be performed below $700{ }^{\circ} \mathrm{C}$, a temperature that will not affect the doping profile of regions already activated at higher temperatures. Likewise, the necessary p-type guard-rings and n-type channel stops that may be essential for keeping the dark current low can be created by implanting and annealing before the anode area of the photodiode is opened for B-deposition. Attention should, however, be paid to the possible autodoping from these pre-fabricated doping regions onto the open anode silicon surface. The position and doping level of extra doping regions must be chosen so that any significant autodoping is avoided if the anode $\mathrm{p}^{+}$region is to remain reliably ultrashallow.

Implementing a p-guard-ring can be particularly important for diodes where the n-doping near the metallurgic junction is high, i.e., more than about $10^{16} \mathrm{~cm}^{-3}$, because the very shallow B-layer junctions have a high curvature at the perimeter giving a correspondingly high electric field that can be the cause of early breakdown and high dark current (Sarrubi, 2010c). Moreover, for such extremely shallow junctions the exact topography of the oxide at the edge of the B-layer deposition window, examples of which are shown in Fig. 3, can have an influence on the resulting I-V characteristics. If the post-deposition processing deteriorates the integrity of the oxide at the diode edge, the distance between the n-Si and the contacting metal may become so small that Schottky-like regions with high currents and even shorts to the metal can occur. A p-guard-ring will protect against such effects. An example of the fabrication of p-type guard-rings and n-type channel stops is given in Section 4.3, Fig. 14, where the fabrication of detectors for SEM systems is treated. 
The processing after the B-layer deposition is highly facilitated by a number of attractive properties of the layer itself. Pure boron has a very high melt temperature, above $2000{ }^{\circ} \mathrm{C}$, and it is chemically inert with respect to many of the back-end processing materials and etchants applied in silicon IC-technology. In Fig. 6 a typical processing scheme is depicted for the processing of the photodiode contact as well as any extra layer needed to cover the front-entrance window, for example for protection, absorption or filtering purposes.

a)
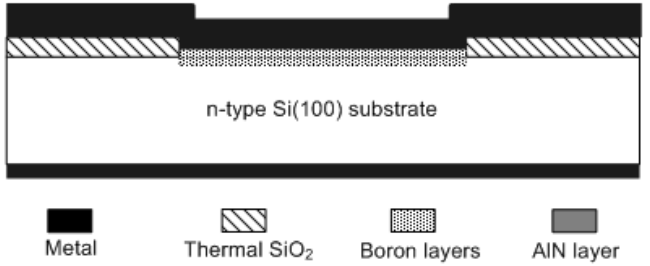

b)

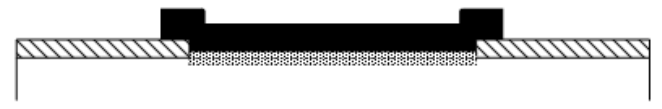

c)

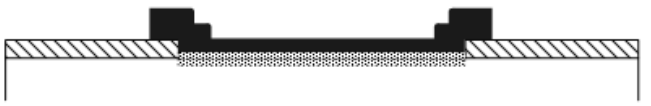

d)

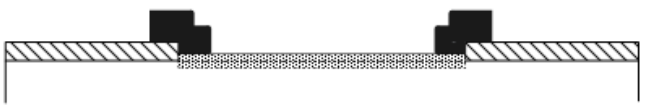

e)

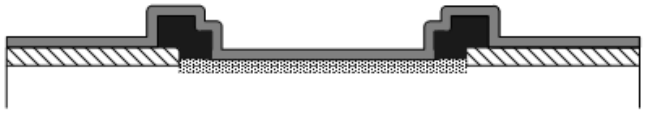

Fig. 6. Schematic of an example of a process flow for anode contact formation when the metal (Al) is deposited directly after the B-layer deposition and removed locally on part of the B-layer region: (a) pure $\mathrm{Al}$ deposition, (b) anode contact definition, (c) dry etching to remove most of the $\mathrm{Al}$ on the region to be opened, (d) dilute HF etching of the remaining $\mathrm{Al}$ using the a-B layer as etch-stop, and (e) deposition of an extra front-entrance window layer (Šakić et al., 2010b).

The high sheet resistance of the B-layer can place a limitation on the series resistance of the photodiode when the as-deposited layer forms the front-entrance window. The series resistance can be significantly lowered by depositing $\mathrm{Al}$ directly on the diode surface and patterning it in a grid. This is possible because the $\mathrm{Al}$ makes good ohmic contact to the a-B layer and it can be selectively removed by etching in HF. This process is in general applied to contact the $\mathrm{p}^{+} \mathrm{B}$-doped silicon through the $\mathrm{a}-\mathrm{B}$ layer, instead of for example contacting through windows in an oxide isolation layer. Due to the high resistivity of the a-B layer the vertical resistance through the layer must also be considered particularly if the contact surface area is small.

The response time of a detector will for millimeter large photodiodes often be dominated by the time constant of the diode RC equivalent circuit formed by the junction capacitance $C_{j}$ and the series resistance $\mathrm{R}_{\mathrm{s}}$. For the $\mathrm{nm}$-deep B-layer diodes without extra surface layers, the sheet resistance of the p-doped $\mathrm{Si}$ can be $\sim 10 \mathrm{k} \Omega / \mathrm{sq}$ or more and this will give the main contribution to the total $R_{S}$ if photo-generated carriers are collected at a peripheral electrode 
after flowing through the thin p-doped region (Xia et al., 2008). However, if the application allows it, the conductivity of the active surface layer can be significantly increased by extending the B-deposition cycle in-situ with extra depositions, such as p-doped $\mathrm{Si}$, and extra thermal drive-in steps, as described in (Sarubbi et al., 2008b). In addition, conductive films can also be deposited directly onto the entire active area. Such coating layers should be properly optimized for the specific application, since optical absorption will occur at the front-entrance window.

The photodiodes with B-layers deposited at $500{ }^{\circ} \mathrm{C}$ offer more flexibility with respect to their integration than the $700{ }^{\circ} \mathrm{C}$ diodes. In principle, they could also be fabricated in a back-end processing module, for example on fully-processed CMOS wafers since these will normally be able to tolerate a temperature of $500{ }^{\circ} \mathrm{C}$. However, although the electrical characteristics of the $500{ }^{\circ} \mathrm{C}$ diodes have been found to be just as ideal as the $700{ }^{\circ} \mathrm{C}$ ones, the reliability of the process is clearly increased by thermally driving the B-dopants further into the $\mathrm{Si}$, thus moving the metallurgic junction away from the surface. At $500{ }^{\circ} \mathrm{C}$ the surface doping is extremely limited and a more thorough optical characterization needs to be made to determine whether this has implications for the degradation and radiation hardness of the photodiodes in the different detector applications. All optical characterization reported in the following was performed on diodes fabricated with $700{ }^{\circ} \mathrm{C}$ B-layer depositions.

\subsection{VUVIDUV radiation detectors}

For the VUV spectral range from $\sim 100 \mathrm{~nm}$ to $\sim 200 \mathrm{~nm}$ the penetration depth in silicon is extremely small as illustrated in Fig. 7. The name "Vacuum UV" refers to the fact that the light is strongly absorbed by air, and the detectors are mainly operated in vacuum. Particularly high-performance deep-ultra-violet (DUV) photodiodes for $193 \mathrm{~nm}$ radiation detection are in high demand due to their application in advanced optical lithography equipment. At this wavelength the penetration depth of the incident radiation in Si is less than $6 \mathrm{~nm}$. However, several materials are transparent at $193 \mathrm{~nm}$, and for example silicon oxides can be used as protection layers that, for the right thickness, may also reduce the reflectivity of the surface thus increasing the responsivity.

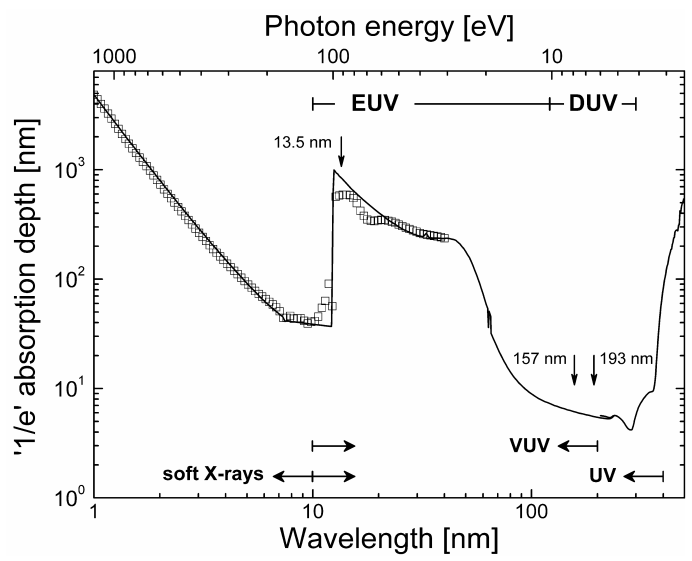

Fig. 7. '1/e' absorption depth in Si as a function of incident radiation wavelength (Palik, 1985; Henke data). 


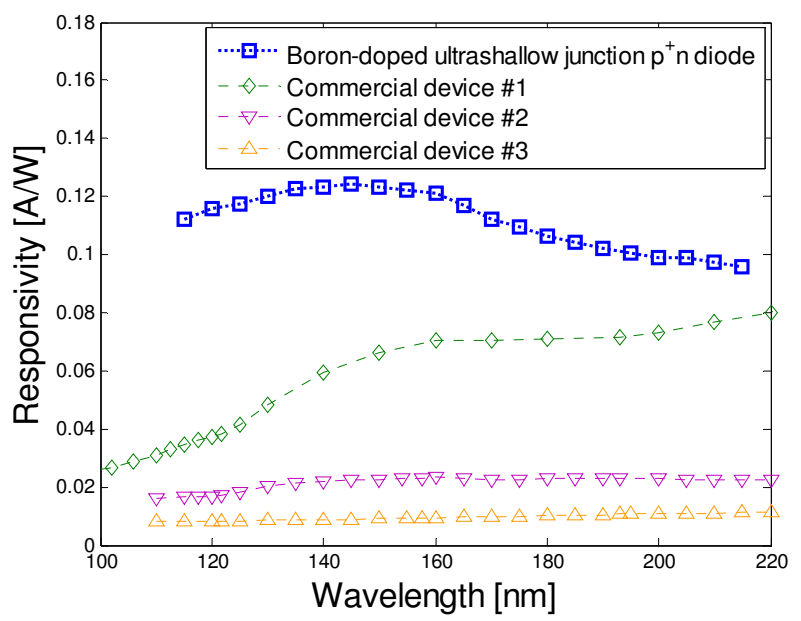

Fig. 8. Responsivity of a B-layer photodiode in the VUV spectral range, compared to three commercially available photodetectors (Shi et al., 2010).

Optical tests were carried out at the synchrotron radiation laboratory of PTB (PhysikalischTechnische Bundesanstalt) in Berlin, Germany (Gottwald et al., 2006, 2010), (Richter et al., 2002). Fig. 8 shows the superior responsivity of the B-layer photodiode compared with other state-of-the-art photodiodes in the VUV spectral range. This excellent optical performance confirms that the B-deposition process can provide ultrashallow and high-quality $\mathrm{p}^{+}$-doped active surface layers, which can effectively enhance the quantum efficiency by reducing the VUV photon absorption in the front window. The dark current has also been found to be low: on circular photodiodes with an active area of $10.75 \mathrm{~mm}^{2}$ (a diameter of $3.7 \mathrm{~mm}$ ) and a reverse biasing of $20 \mathrm{~V}$, the current was only $\sim 30 \mathrm{pA}$ as compared to $\sim 730 \mathrm{pA}$ for the available commercial diodes of the same area.

The robustness of these diodes was extensively investigated by applying high-dose and/or extended exposures, and it could be concluded that there was no significant responsivity degradation. In all cases, any observed degradation could be related to irradiation-induced charging phenomena. To minimize such effects, the active surface should be made as conductive as possible. This is achieved on diodes with $\mathrm{a}-\mathrm{B}$ as the top surface layer by avoiding oxidizing post-treatments that create thick native/chemical oxides. In air, the asdeposited $\mathrm{a}-\mathrm{B}$ layer does not form a native oxide of any significant thickness. To reduce the effective sheet resistance of the anode surface, the aluminum anode contact-metal can be extended to form a grid over the diode surface as, for example, illustrated in Fig. 9. The trade-off is that this additional Al-grid will reduce the effective light-sensitive surface area. In Fig. 10, an example is given of the spectral responsivity during long exposures, in this case for the Al-grid diode monitored for one hour during VUV irradiation at a wavelength of $70 \mathrm{~nm}$. As indicated, the decrease in responsivity stays within 1\%. All in all, for VUV radiation detection the B-layer photodiode technology has demonstrated excellent electrical and optical performance in terms of extremely low dark current, outstanding responsivity, and high stability to extended exposures. 


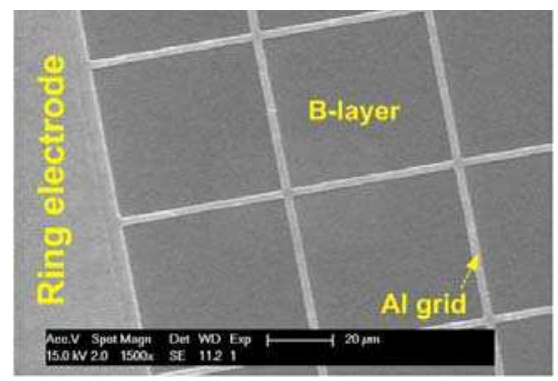

Fig. 9. Photograph of one corner of a photodiode with an Al-grid processed directly on the B-layer anode surface.

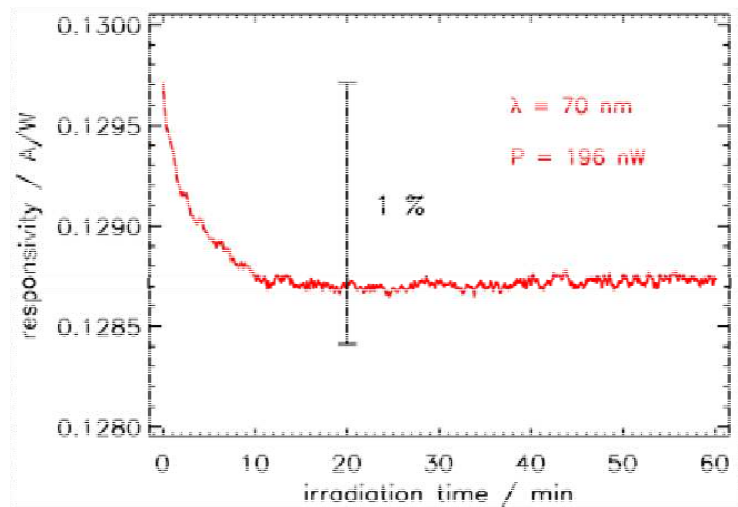

Fig. 10. Degradation of the responsivity of a photodiode with a $\sim 3$-nm-thick a-B layer and an Al-grid under irradiation at a wavelength of $70 \mathrm{~nm}$ as a function of the irradiation time (Shi et al., 2010).

\subsection{EUV radiation detectors}

The extreme-ultra-violet (EUV) wavelength of $13.5 \mathrm{~nm}$ has been selected by ASML Lithography for future EUV lithography equipment, which has been under serious development since 2006 and is forecast to be in high-volume production by 2015 (Benschop et al., 2008). This has spurred interest in photodiode detectors for this wavelength. At the moment the B-layer photodiodes are the only devices qualified for application in the EUV wafersteppers for monitoring the light entering the alignment system from the source (the energy sensor) and for effectuating the actual wafer alignment to the mask (with the transmission imaging sensor and the spot-slit sensor). The penetration depth in Si of this almost soft X-ray light at $13.5 \mathrm{~nm}$ is large compared to that of the DUV light, about $700 \mathrm{~nm}$, but the degradation issues are much more severe. Detectors have been fabricated with a number of other on-chip components such as bipolar transistor temperature sensors and optical filter/absorber layers. The latter can be deposited directly on the B-layer surface. For example, zirconium is an attractive filter layer for higher wavelength light (Powell et al., 2010). Moreover, it has the advantage of being metallic with good electrical conductivity, so a surface layer of zirconium can also significantly lower the diode series resistance. 
As done for the VUV diodes, the EUV optical characterization was performed at PTB (Klein et al., 2006). A measurement example is shown in Fig. 11 for two B-layer diodes with different surface layers. The one with a $\sim 3$-nm-thick as-deposited a-B layer as front-entrance window has a responsivity of $0.266 \mathrm{~A} / \mathrm{W}$, which is practically that of an ideal lossless system estimated to be 0.273 A/W (Scholze et al., 1998, 2000). This is higher than what was obtained with any of the commercial photodiodes that also were characterized at $13.5 \mathrm{~nm}$.

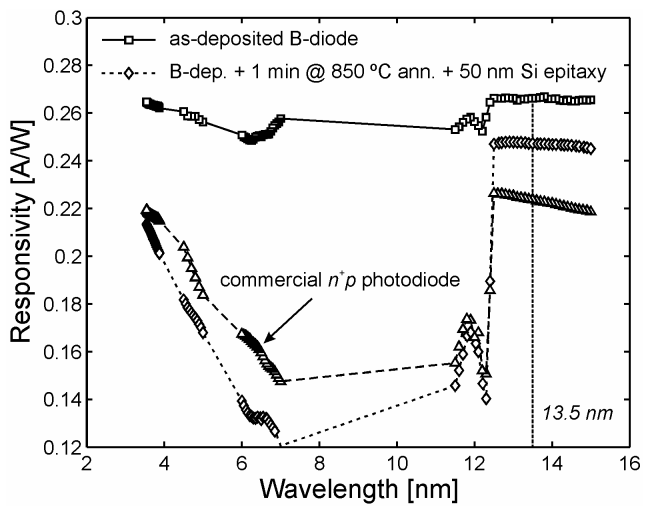

Fig. 11. Measured spectral responsivity (symbols) of B-layer photodiodes with a surface layer of $\sim 3 \mathrm{~nm}$ thick $\mathrm{a}-\mathrm{B}$, with and without an extra in-situ $850{ }^{\circ} \mathrm{C}$ thermal anneal and $50 \mathrm{~nm}$ epitaxially deposited B-doped $\mathrm{Si}$, compared to a commercial state-of-the-art $\mathrm{n}^{+} \mathrm{p}$ photodiode (Sarubbi et al., 2008b).

The degradation of the photodiodes was characterized by prolonged high-dose exposure $\left(0.22 \mathrm{MJ} / \mathrm{cm}^{2}\right.$ during $\left.24.5 \mathrm{~h}\right)$ to $13.5 \mathrm{~nm}$ radiation, and no change in the responsivity due to degradation of the detector itself was observed. As for the corresponding radiation-induced degradation of the electrical behavior, an increase of the photodiode dark current level from below a $\mathrm{nA}$ to tens of $\mathrm{nA}$ at a reverse bias of $10 \mathrm{~V}$ was observed. This effect is common in silicon-based photodiodes, but here the dark current degradation was found to be annealed out by thermal treatment at relatively low temperatures, such as $\sim 200{ }^{\circ} \mathrm{C}$, indicating that this is an oxide-related degradation due to charging of the oxide around the diode perimeter. Since for the operating conditions of detectors in future applications the biasing is being scaled down to the $\mathrm{mV}$ range, the sensitivity to radiation-induced dark current will be quite low. As for the VUV case, it can be concluded that for EUV applications the B-layer photodiodes exhibit superior responsivity and negligible degradation under high-power exposure. The B-layer photodiodes have superior responsivity and negligible degradation under high-power exposure to EUV light.

\subsection{Low-energy electron detectors}

In contrast to photodiodes for DUV/EUV detectors, where protective entrance window layers can be found that are fairly transparent to the light, low-energy electron detectors require an entrance window that is essentially free of non-sensitive layers. This is obvious from the projected ranges in matter that have been compiled and are summarized in Fig. 12. At an electron energy of $10 \mathrm{keV}$ the penetration depth is around $1 \mu \mathrm{m}$, a depth that is manageable for many conventional silicon photodiodes, but already at $2 \mathrm{keV}$ it drops to about $200 \mathrm{~nm}$ and decreases rapidly to the $10-40 \mathrm{~nm}$ range at $1 \mathrm{keV}$. At $500 \mathrm{eV}$ it is already 
below $\sim 10 \mathrm{~nm}$, so to have any form of practical responsivity this dictates that all nonsensitive surface layers must be nm-thin. The fact that the B-layer diodes can meet this requirement and are easily integrated in silicon has led to a very fast commercialization of the detectors in scanning electron microscopes.

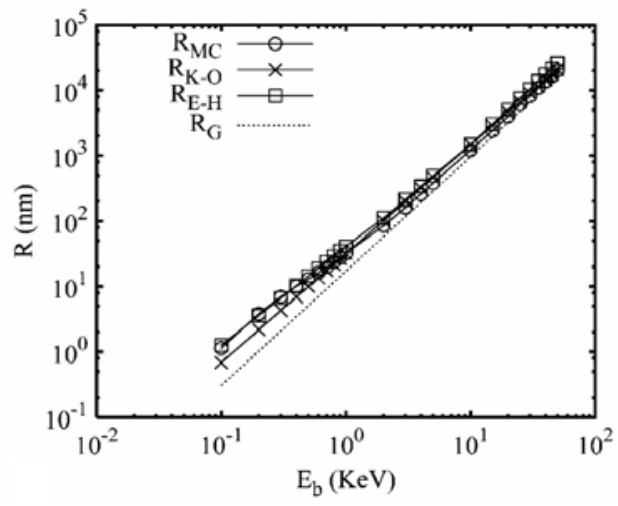

Fig. 12. Electron range $\mathrm{R}$ in $\mathrm{Si}$ as a function of electron energy $\mathrm{E}_{\mathrm{b}}$ (Kurniawan \& Ong, 2007).

Low-voltage SEM imaging is widely used for nanometer-scale inspection, among other things in the semiconductor industry. It provides atomic-scale resolution of the specimen surface due to the short range of electrons in matter. Lowering the electron energy gives more surface information and better resolution. Moreover, charging effects become less prominent than for higher voltages where they readily obscure the imaging of the non-conducting materials. The B-layer detectors that have been fabricated for low-energy electron detection are a good example of the versatility of the overall processing capabilities in Si technology. Exceptional imaging capabilities were obtained by the implementation of the following unique (combinations of) processing techniques:

- the B-layer photodiodes themselves, where $\mathrm{a} \sim 2 \mathrm{~nm}$ thin amorphous boron ( $\mathrm{a}-\mathrm{B}$ ) layer forms the front-entrance window. The low atomic number of the B is also instrumental in minimizing scattering of the incoming electrons, thus allowing a longer projected range in the detector;

- compact segmented anode layouts, where the photosensitive surface is maximized and low diode capacitance is combined with lateral junction isolation of the segments. This is achieved by epitaxially growing very lightly-doped, tens-of-microns thick n-layers on low-ohmic n-type substrates;

- low photodiode series resistance combined with a large sensitive front-window area by patterning a fine aluminum grid directly on the $\mathrm{a}-\mathrm{B}$ surface. The low series resistance and capacitance values combine to give low transit times and thus high scanning speeds;

- through-wafer apertures etched close to the anode regions for detectors designed to monitor back-scattered electrons (BSE) in SEM systems such as the one shown in Fig. 13. This is a back-end processing step that would damage the delicate a-B surface layer if it was not protected during the through-wafer hole etching. Therefore, a processing 
scheme was developed whereby the final removal of all Al down to the photo-sensitive regions is the very last step of the wafer-scale processing.

In Fig. 14 an illustration is given of the final detector structure with the segmented photodiode layout. A variety of detectors have been fabricated in this way and tested for specific functions in several different SEM systems. An example of the resulting highresolution images that can be obtained is shown in Fig. 15. By using different read-out sequences of segments in this annular BSE detector an optimal contrast can be attained.

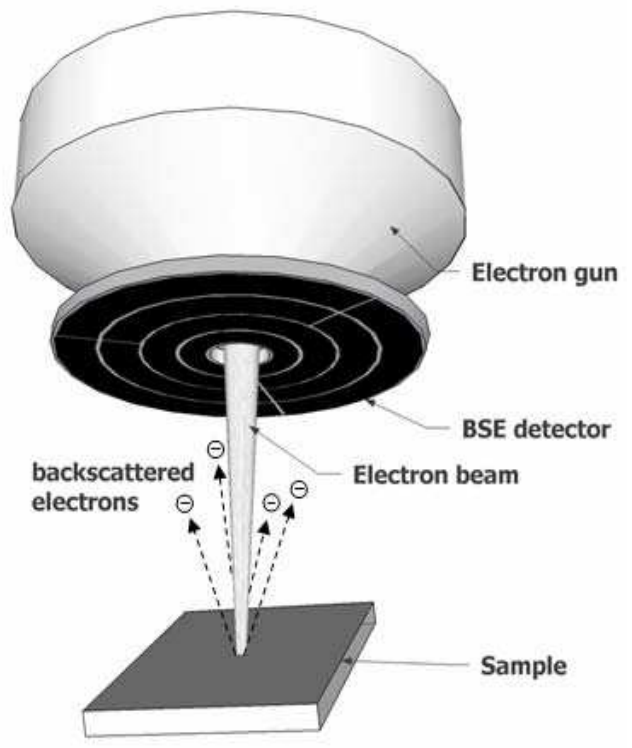

Fig. 13. Conceptual drawing of a SEM system showing the location of an annular BSE detector.

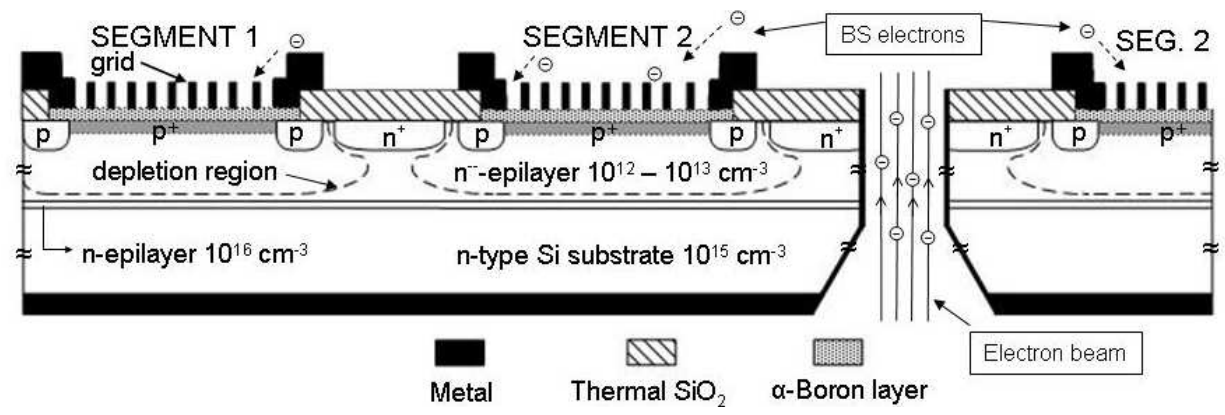

Fig. 14. Schematic cross-section of two neighboring segments of a B-layer detector with a through-wafer hole as aperture for the electron beam. The depletion of the typically $40 \mu \mathrm{m}$ deep $\mathrm{n}^{--}$epitaxial layer is indicated. Segments are isolated by the $\mathrm{n}^{+}$-channel-stop and the undepleted n---layer (Šakić et al., 2010c). 


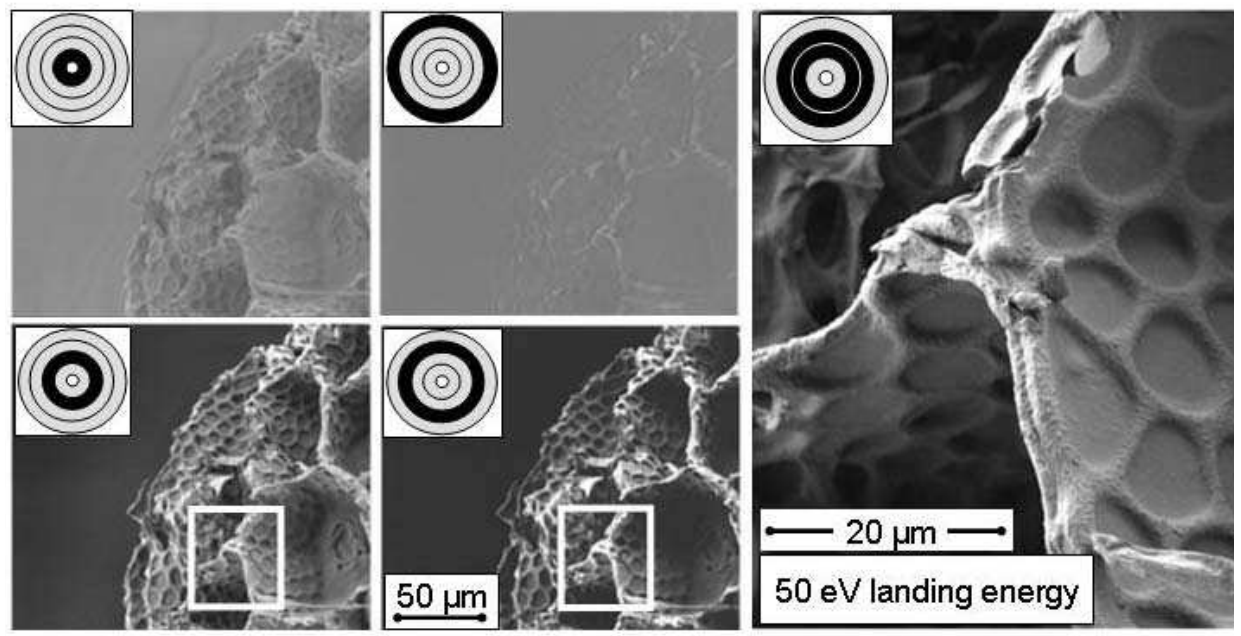

Fig. 15. Imaging of an uncoated pollen sample at $50 \mathrm{eV}$ landing energy. The BSE detector is divided in 8 annular segments that can be operated in various combinations as shown in the inset. The best resolution is obtained with the combination of segments used to produce the image to the right (Šakić et al., 2010c).

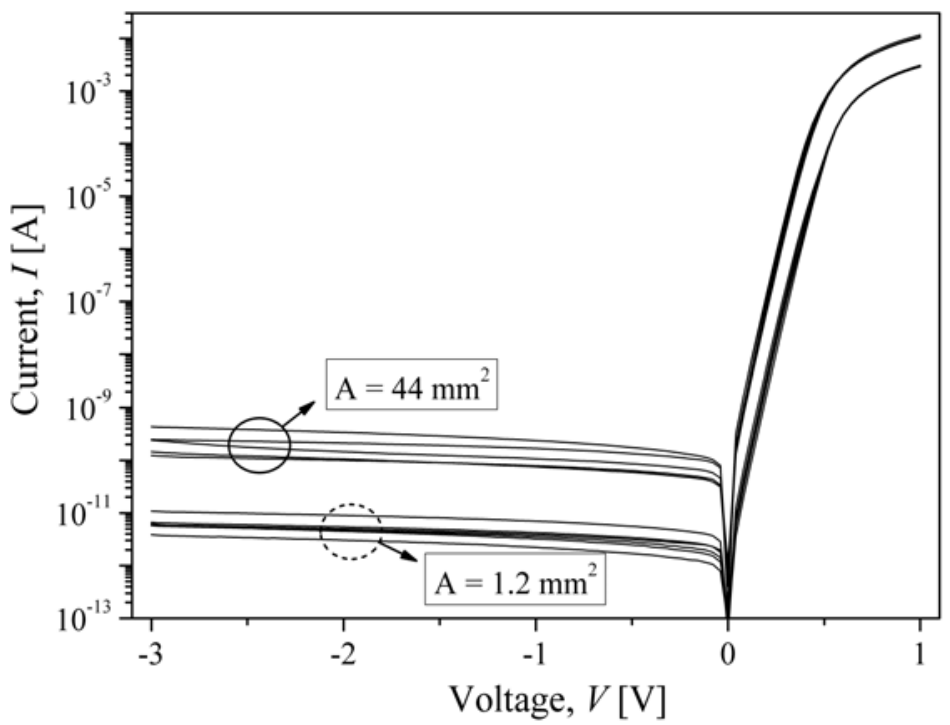

Fig. 16. On-wafer measurements of the I-V characteristics of two types of B-layer diodes with areas $44 \mathrm{~mm}^{2}$ and $1.2 \mathrm{~mm}^{2}$, respectively. They form 2 out of 8 segments of a BSE detector. For the larger diodes, characteristics are shown for devices with and without a conductive Al-grid on the photosensitive surface (Šakić et al., 2010b). 


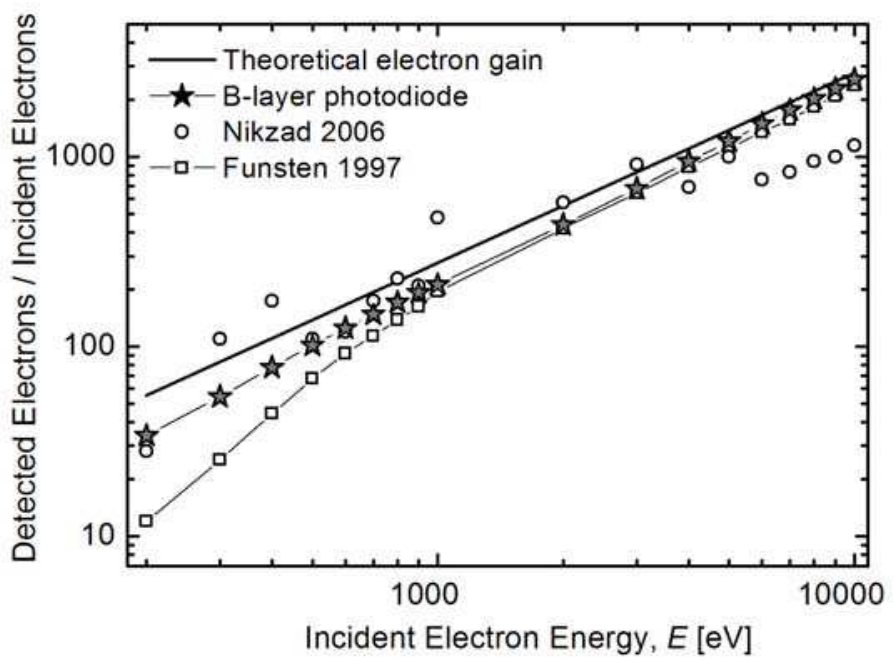

Fig. 17. Measured electron gain of a B-layer photodiode compared to the data reported by (Nikzad et al., 2006) and (Funsten et al., 1997), compared to the theoretical electron gain (Šakić et al., 2010c).

An example of the electrical characteristics of 2 out of 8 photodiode segments of a BSE detector are shown in Fig. 16. The beneficial effect of the Al-grid on the series resistance is seen in the high current forward bias region. Also, a reliably low dark current is seen in the reverse bias region. The electron gain of B-layer photodiodes is shown in Fig. 17. It is measured using the electron beam of a SEM system as electron source, a Faraday cup to measure the reference electron beam current (incident electrons), and a reverse biasing of $3 \mathrm{~V}$ is applied to the photodiode during electron detection. Also included are values for other low-energy electron detectors reported in the literature by (Nikzad et al., 2006) and (Funsten et al., 1997). In addition, the theoretical value of the gain is calculated as the incident energy of the electron beam over the creation energy of an electron-hole pair in silicon of $3.61 \mathrm{eV}$. Although the gain values at low electron energies reported in (Nikzad et al., 2006) are high, they are unreliable due to noise and do not exhibit clear energy dependence. Furthermore, the sensitivity in the region above $4 \mathrm{keV}$ drops off significantly. B-layer photodiodes show the expected energy dependence and operate closer to the theoretical limits than those reported in (Funsten et al., 1997), especially below $1 \mathrm{keV}$. At 500 $\mathrm{eV}$ and $1 \mathrm{keV}$, they have an electron signal gain at low energies of $60 \%$ and $74 \%$ of the theoretical gain value, respectively. 


\section{Conclusion}

The three industrial detector applications of the presented B-layer photodiodes, i.e., DUV, EUV and low-energy electron detectors, demonstrate the high performance and integration versatility of this silicon technology. The special doping properties of the low-temperature $\mathrm{a}-\mathrm{B}$ deposition and the electrical properties of the $\mathrm{a}-\mathrm{B}$ layer itself are instrumental in securing a damage-free extremely shallow diode that provides superior performance in terms of dark current, optical responsivity, and radiation induced degradation. The DUV/VUV/EUV photodiodes can be implemented to obtain close to $100 \%$ internal and external quantum efficiency, and low-energy electron detection with record-high sensitivity has been demonstrated down to $200 \mathrm{eV}$. Moreover, the silicon fabrication technology is highly reliable and enables flexible configurations of the diodes and other on-chip components, enhancing the detector speed and functionality. This is particularly demonstrated by the low RC constant of the low-energy electron detectors combined with a segmented photodiode design and a through-wafer aperture.

\section{Acknowledgements}

This chapter summarizes the work of a large group of people to whom the author is greatly indebted. Firstly, thanks go to the original team: Tom Scholtes for the processing experiments, Francesco Sarubbi for measurement/analysis of the experimental material and Koen Buisman for designing the first B-layer diode circuits. Stoyan Nihtianov is acknowledged for securing the ASML DUV/EUV lithography projects and for his work together with Lei Shi producing detector designs and analysing many aspects of the photodiodes in this context. This UV work was performed in fruitful cooperation with PTB, particularly Frank Scholze, Alexander Gottwald and Udo Kroth, who are responsible for the DUV/VUV/EUV optical measurements and interpretations. Thanks are due to Gerard van Veen, Kees Kooijmans and Patrick Vogelsang of FEI Company for two and a half years of intensive and very productive cooperation on the research and development of low-energy electron detectors for scanning electron microscopes. At DIMES the electron detector research was realized mainly by Agata Šakić, Silvana Milosavljević, Negin Golshani, Wim Wien, Caroline Mok and Carel Heerkens, but the success is also a credit to the whole DIMES IC-Processing group, headed by Bert Goudena, for maintaining an outstanding cleanroom. Lastly, the author gratefully acknowledges Gianpaola Lorito, Luigi La Spina, Theodoros Zoumpoulidis and Jaber Derakhshandeh of Iszgro Diodes for bringing this work to a production level, which, particularly for the EUV detectors, has in no way been a trivial task. Beside the industrial support from ASML Lithography and FEI Company, this research has profited from support from and cooperation with the SmartMix project MEMPHIS and Project No. 10024 of The Dutch Technology Foundation STW.

\section{References}

Canfield, L. R.; Vest, R. E ; Korde, R.; Schmidtke, H. \& Desor, R. (1998) Absolute silicon photodiodes for $160 \mathrm{~nm}$ to $254 \mathrm{~nm}$ photons. Metrologia, Vol. 35, No. 4, (1998) pp. 329-334, ISSN 0026-1394 
Benschop, J.; Banine, V.; Lok, S. \& Loopstra, E. (2009). Extreme ultraviolet lithography: Status and prospects. Journal of Vacuum Science \& Technology B: Microelectronics and Nanometer Structures, Vol. 26, Issue 6, (November 2008) pp. 2204 - 2207, ISSN 10711023

Borland, J.O.; Felch, S.; Wan, Z.; Tanjyo, M.; \& Buyuklimanli, T. (2009). Thermal processing issues for 22nm node junction scaling. Solid State Technology, Vol. 52, Issue 8, (August 2009) pp. 1-8

Funsten, H. O.; Suszcynsky, D. M.; Ritzau, S. M \& Korde, R. (1997). Response of 100\% internal quantum efficiency silicon photodiodes to $200 \mathrm{eV}-40 \mathrm{keV}$ Electrons. IEEE Transactions on Nuclear Science, Vol. 44, Issue 6, (1997) pp. 2561-2565, ISSN 0018-9499

Funsten, H. O.; Ritzau, S. M. \& Harper, R. W. (2004). Fundamental limits to detection of lowenergy ions using silicon solid-state detectors. Applied Physics Letters, Vol. 84, no. 18, (April 2004) pp. 3552-3554, ISSN 0003-6951

Gottwald, A.; Kroth, U.; Krumrey, M.; Richter, M.; Scholze, F. \& Ulm, G. (2006). The PTB high-accuracy spectral responsivity scale in the VUV and x-ray range, Metrologia, Vol. 43, Issue Newrad 2005, (April 2006) pp. S125-S129, ISSN 0026-1394

Gottwald, A.; Kroth, U.; Richter, M.; Schöppe, H. \& Ulm, G. (2010). Ultraviolet and vacuum-ultraviolet detector-based radiometry at the Metrology Light Source, Measurement Science and Technology, Vol. 21, No. 12, (December 2010) pp. 1-9, ISSN 0957-0233

Henke data. (no date) Available from <http://henke.lbl.gov/optical_constants>

Inada, T.; Kuranouchi, A.; Hirano, H.; Nakamura, T.; Kiyota, Y. \& Onai, T. (1991). Formation of ultrashallow $\mathrm{p}^{+}$layers in silicon by thermal diffusion of boron and by subsequent rapid thermal annealing. Applied Physics Letters, Vol. 58, No.16, (April 1991) pp. 1748-1750, ISSN 0003-6951

ITRS 2009 Edition, International Technology Roadmap for Semiconductors 2009. Avaibable from <http://www.itrs.net>

Kurniawan, O. \& Ong, V. K. S. (2007). Investigation of Range-energy Relationships for Lowenergy Electron Beams in Silicon and Gallium Nitride. Scanning, Vol. 29, Issue 6, (October 2007) pp. 280-286, , ISSN 0161-0457

Kim, K.-S.; Song, Y.-H.; Park, K.-T.; Kurino, H.; Matsuura, T.; Hane, K. \& Koyanagi, M. (2000). A novel doping technology for ultra-shallow junction fabrication: boron diffusion from boron-adsorbed layer by rapid thermal annealing. Thin Solid Films, Vol. 369, Issues 1-2, (July 2000) pp. 207-212, ISSN 0040-6090

Klein, R.; Laubis, C.; Müller, R.; Scholze, F. \& Ulm, G. (2006). The EUV metrology program of PTB, Microelectronic Engineering, Vol. 83, Issue 4-9, (January 2006) pp. 707-709, ISSN 0167-9317

Nikzad, S.; Cunningham, T. J.; Hoenk, M. E.; Ruiz, R. P.; Soules, D. M. \& Holland S.E. (2006). Direct detection of $0.1-20 \mathrm{keV}$ electrons with delta doped, fully depleted, high purity silicon $p-i-n$ diode arrays. Applied Physics Letters, Vol. 89, Issue 18, (October 2006) pp. 182114-1-3, ISSN 0003-6951

Palik, E.D. (Ed.). (1985). Handbook of Optical Constants of Solids. Academic Press, Incorperated, Orlando, Florida 
Popadic, M.; Lorito, G. \& Nanver, L.K. (2009). Analytical carrier transport model for arbitrarily shallow p-n junctions. IEEE Trans. Electron Devices, Vol. 56, Issue 1, (January 2009) pp. 116-125, ISSN 0018-9383

Powell, F.R. \& Johnson, T.A. (2010). Filter windows for EUV lithography. Available from <http://www.luxel.com/wp/wp-content/uploads/2010/04/EUVL-Paper.pdf>

Richter, M.; Kroth, U.; Gottwald, A.; Gerth, C.; Tiedtke, K.; Saito, T.; Tassy, I. \& Vogler, K. (2002). Metrology of pulsed radiation for 157-nm lithography. Applied Optics, Vol. 41, Issue 34, (December 2002) pp. 7167-7172, , ISSN 2155-3165

Sarubbi, F. (2010c). "Characterization of pure boron depositions integrated in silicon diodes for nanometer-deep junction applications", Ph.D. dissertation, Delft University of Technology, ISBN 978-90-8570-436-2, Delft, The Netherlands

Šakić, A.; Jovanović, V.; Maleki, P.; Scholtes, T.L.M.; Milosavljević, S. \& Nanver, L.K. (2010a). Characterization of amorphous boron layers as diffusion barrier for pure aluminium. Proceedings of 33rd International Convention MIPRO, Vol. 1, pp. 52-55, ISBN 978-953-233-051-9, Zagreb, Croatia, May 2010

Šakić, A.; Nanver, L.K.; Heerkens, C.Th.H.; Veen, G. van; Kooijman, K. \& Vogelsang, P. (2010b). Silicon photodiodes for high-efficiency low-energy electron detection. Proceedings of IEEE 40th European Solid-State Device Research Conference (ESSDERC), pp. 102-105, ISBN 978-1-4244-6659-7, Sevilla, Spain, September 2010

Šakić, A.; Nanver, L.K.; Veen, G. Van; Kooijman, K.; Vogelsang, P.; Scholtes, T.L.M.; Boer, W. de; Wien, W.H.A.; Milosavljević, S.; Heerkens, C.Th.H.; Knežević, T. \& Spee, I. (2010c). Versatile Silicon Photodiode Detector Technology for Scanning Electron Microscopy with High-Efficiency Sub-5 keV Electron Detection. Proceedings of IEEE International Electron Device Meeting (IEDM), pp. 712 -715, ISBN 978-1-4244-7419-6, San Francisco, California, December 2010

Sarubbi, F.; Nanver, L.K.; \& Nihtianov, S.N. (2008a). Extremely ultra-shallow $\mathrm{p}^{+}-\mathrm{n}$ borondeposited silicon diodes applied to DUV photodiodes. Digest IEEE $66^{\text {th }}$ Device Research Conference (DRC), pp. 143-144, ISSN 1548-3770, Santa Barbara, CA, USA, June 2008

Sarubbi, F.; Nanver, L.K.; Scholtes, T.L.M.; Nihtianov, S.N. \& Scholze, F. (2008b). Pure boron-doped photodiodes: a solution for radiation detection in EUV lithography. Proceedings of IEEE 38th European Solid-State Device Research Conference (ESSDERC), pp. 278-281, ISSN 1930-8876, Edinburgh, Scotland, UK, September 2008

Sarubbi, F.; Scholtes, T.L.M. \& Nanver, L.K. (2010a). Chemical vapor deposition of a-boron layers on silicon for controlled nanometer-deep $\mathrm{p}^{+} \mathrm{n}$ junction formation. Journal of Electronic Materials, Vol. 39, No. 2, (February 2010) pp. 162-173, ISSN 03615235

Sarubbi, F.; Nanver, L.K. \& Scholtes, T.L.M. (2010b). High effective Gummel number of CVD boron layers in ultrashallow $\mathrm{p}^{+} \mathrm{n}$ diode configurations. IEEE Transactions on Electron Devices, Vol. 57, Issue. 6, (June 2010) pp. 1269-1278, ISSN 0018-9383

Scholze, F.; Rabus, H. \& Ulm, G. (1998). Mean energy required to produce an electron-hole pair in silicon for photons of energies between 50 and $1500 \mathrm{eV}$. Journal of Applied Physics, Vol. 84, No. 5, (September 1998) pp. 2926-2939, ISSN 0021-8979 
Scholze, F.; Henneken, H.; Kuschnerus, P.; Rabus, H.; Richter, M. \& Ulm, G. (2000). Determination of the electron-hole pair creation energy for semiconductors from the spectral responsivity of photodiodes. Nuclear Instruments and Methods in Physics Research, section A, Vol. 439, Issue 2-3, (2000) pp. 208-215, ISSN 0168-9002

Shi, L.; Sarubbi, F.; Nihtianov, S.; Nanver, L.K.; Scholtes, T.L.M. \& Scholze, F. (2009), High Performance Silicon-Based Extreme Ultraviolet (EUV) Radiation Detector for Industrial Application, Proceedings of IEEE Conference on Industrial Electronics (IECON), pp. 1891-1896, Porto, Portugal, November 2009

Shi, L.; Nanver, L.K.; Šakić, A.; Nihtianov, S.; Gottwald, A. \& Kroth, U. (2010). Optical Stability Investigation of High-Performance Silicon-Based VUV Photodiodes. Proceedings of IEEE Sensors 2010 Conference, Waikoloa, USA, November 2010

Silver C. S.; Spallas J.P. \& Muray L.P. (2006). Silicon photodiodes for low-voltage electron detection in scanning electron microscopy and electron beam lithography. Journal of vacuum science E technology B, Vol. 24, Issue 6, (2006) pp. 2951-2955, ISSN 0734-211X

Solt, K.; Melchior, H.; Kroth, U.; Kuschnerus, P.; Persch, V.; Rabus, H.; Richter, M. \& Ulm, G. (1996). PtSi-n-Si Schottky-barrier photodetectors with stable spectral responsivity in the 120-250 nm spectral range. Applied Physics Letters, vol. 69, Issue 24, (December 1996) pp. 3662-3664, , ISSN 0003-6951

Sarubbi, F. (2010). "Characterization of pure boron depositions integrated in silicon diodes for nanometer-deep junction applications", Ph.D. dissertation, Delft University of Technology, ISBN 978-90-8570-436-2, Delft, The Netherlands

Tindall, C.S.; Palaio, N.P.; Ludewigt, B.A.; Holland, S.E.; Larson, D. E.; Curtis, D. W.; McBride, S. E.; Moreau, T.; Lin, R. P. \& Angelopoulos, V. (2008), Silicon detectors for low energy particle detection. IEEE Transactions on Nuclear Science, Vol. 55, Issue 2, (April 2008) pp. 797-801, ISSN 0018-9499

Vick, G.L. \& Whittle, K.M. (1969). Solid solubility and diffusion coefficients of boron in Si. Journal of the Electrochemical Society, Vol. 116, issue 8, (August 1969) pp. 1142-1144, ISSN 0013-4651

Xia, S.; Sarubbi, F.; Naulaerts, R.; Nihtianov, S.N. and Nanver, L.K. (2008). Response time of silicon photodiodes for DUV/EUV radiation. Proc. 2008 IEEE International Instrumentation and Measurement Technology Conference (I2MTC), pp. 1956-1959, ISSN 1091-5281, Victoria, Vancouver Island, Canada, May 2008 


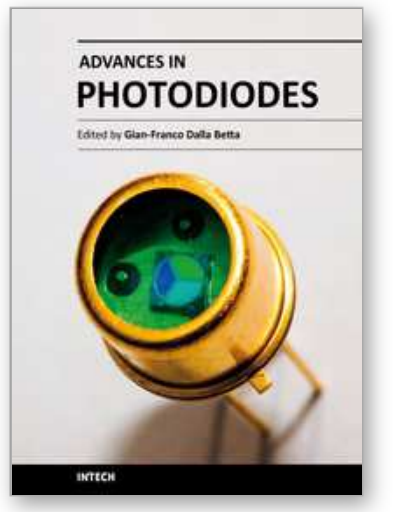

\author{
Advances in Photodiodes \\ Edited by Prof. Gian Franco Dalla Betta
}

ISBN 978-953-307-163-3

Hard cover, 466 pages

Publisher InTech

Published online 22, March, 2011

Published in print edition March, 2011

Photodiodes, the simplest but most versatile optoelectronic devices, are currently used in a variety of applications, including vision systems, optical interconnects, optical storage systems, photometry, particle physics, medical imaging, etc. Advances in Photodiodes addresses the state-of-the-art, latest developments and new trends in the field, covering theoretical aspects, design and simulation issues, processing techniques, experimental results, and applications. Written by internationally renowned experts, with contributions from universities, research institutes and industries, the book is a valuable reference tool for students, scientists, engineers, and researchers.

\title{
How to reference
}

In order to correctly reference this scholarly work, feel free to copy and paste the following:

Lis K. Nanver (2011). Silicon Photodiodes for Low Penetration Depth Beams such as DUV/VUV/EUV Light and Low-Energy Electrons, Advances in Photodiodes, Prof. Gian Franco Dalla Betta (Ed.), ISBN: 978-953-307-1633, InTech, Available from: http://www.intechopen.com/books/advances-in-photodiodes/silicon-photodiodes-forlow-penetration-depth-beams-such-as-duv-vuv-euv-light-and-low-energy-electro

\section{INTECH}

open science | open minds

\section{InTech Europe}

University Campus STeP Ri Slavka Krautzeka 83/A 51000 Rijeka, Croatia Phone: +385 (51) 770447

Fax: +385 (51) 686166 www.intechopen.com

\section{InTech China}

Unit 405, Office Block, Hotel Equatorial Shanghai No.65, Yan An Road (West), Shanghai, 200040, China 中国上海市延安西路65号上海国际贵都大饭店办公楼405单元 Phone: +86-21-62489820

Fax: +86-21-62489821 
(C) 2011 The Author(s). Licensee IntechOpen. This chapter is distributed under the terms of the Creative Commons Attribution-NonCommercialShareAlike-3.0 License, which permits use, distribution and reproduction for non-commercial purposes, provided the original is properly cited and derivative works building on this content are distributed under the same license. 